\title{
Congenital Intracranial Vascular Malformations in Children ${ }^{\star}$
}

\author{
JORGE C. LAGOS and HARRIS D. RILEY, JR. \\ From the Departments of Pediatrics and Neurology, The Children's Memorial Hospital, University of Oklahoma Medical \\ Center, Oklahoma City, Oklahoma, U.S.A.
}

\begin{abstract}
Lagos, J. C., and Riley, H. D. (1971). Archives of Disease in Childhood, 46, 285. Congenital intracranial vascular malformations in children. The clinical, laboratory, and other features of 16 children with congenital intracranial vascular malformations seen over a period of 15 years are presented. 13 patients had an arteriovenous (AV) malformation, 2 patients an aneurysm of the vein of Galen, and 1 a congenital internal carotid/internal jugular fistula. Based on onset of symptoms the patients ranged in age from 3 months to 16 years with an average age of $7 \frac{1}{2}$ years; however, 5 patients had their first clinical manifestation before 6 years of age. Unfortunately, definitive diagnosis could not be made until an average of $15 \frac{1}{2}$ years.

The most important clinical manifestations were focal or generalized seizures and spontaneous intracranial bleeding, each occurring in 6 patients. Of 2 patients who presented with hydrocephalus, 1 had had an unexplained episode of cardiac failure during infancy. Inequality in the size of the legs, and periodic headaches were the initial manifestations in 2 other patients. Analysis of this series of patients with intracranial AV malformations suggests the following diagnostic recommendations: careful auscultation of the skull for bruits should be performed in all infants and children with cardiac failure of unknown aetiology; patients with focal seizures refractory to anticonvulsant therapy should be re-examined at frequent intervals to detect focal neurological deficit which otherwise may go unnoticed; and, finally, patients with a seizure disorder who develop focal signs of neurological deficit deserve a complete diagnostic investigat ion, including contrast studies.
\end{abstract}

Cerebrovascular accidents secondary to congenital intracranial vascular malformations are a not unusual cause of death and of serious neurological disability in adults. The most common congenital lesions are arteriovenous malformations or angiomas and arterial aneurysms. Though the clinical expression or complications of such lesions may not appear until adult life, they are by definition present at birth. Despite this and the fact that a certain number of patients do exhibit clinical manifestations during infancy and childhood, the diagnosis is made infrequently during these age periods. In the series of 110 intracranial angiomas reported by Paterson and McKissock (1956), 10\% of patients exhibited symptoms during the first decade and in

Received 24 August 1970.

* Some of the studies described were supported in part by grant No. C-73 from The National Foundation supporting the Clinical Study for Birth Defects and by grant No. 2 MO1 RR00062-08 from The National Institutes of Health supporting the Clinical Research Center, both located at the Children's Memorial Hospital. only two instances was the diagnosis made during childhood. In another series (Olivecrona and Riives, 1948) of 43 cases of arteriovenous (AV) malformations, 3 became symptomatic during childhood. Only an occasional article has discussed this disorder in childhood (Gold, Ransohoff and Carter, 1964; Paillas et al., 1956; Leites, 1957; Thomson, 1959; Carroll and Jakoby, 1966; Pailles et al., 1958; Lagos and Siekert, 1969).

We report here our experience with congenital intracranial vascular malformations in infants and children.

\section{Case Material}

The present study includes 16 patients with cerebral AV malformations seen over a period of 15 years. 11 of these were seen at Children's Memorial Hospital, University of Oklahoma Medical Center, and 5 were patients at the Vanderbilt University Hospital, Nashville, Tennessee studied by one of the authors (H.D.R., Jr.). Only patients who had definite signs or symptoms before the age of 16 years and in whom the diagnosis was 
proved by angiography, surgery, or pathology have been included. During this same period, 8 patients with Sturge-Weber syndrome were seen at the Children's Memorial Hospital, University of Oklahoma Medical Center, but are not included in this series (Gilmartin and Riley, 1965).

\section{Results}

Table I shows the sex, age of onset, age at diagnosis, initial clinical manifestation, presenting signs or symptoms at the time of diagnosis, and types of lesions.

The distribution of the type of vascular lesion in the 16 patients was as follows: $13 \mathrm{AV}$ malformations; 2 aneurysms of the vein of Galen; and 1 internal carotid internal/jugular fistula. There were 11 males and 5 females. Based on onset of first symptoms, the patients ranged in age from 3 months to 16 years. The average age at onset of the initial clinical manifestation was $7 \frac{1}{2}$ years and the average age at diagnosis was $15 \frac{1}{2}$ years. The onset of the first symptoms occurred during the first year of life in 3 patients, between 1 and 5 years in 2 , between 6 and 10 years in 5 , and between 11 and 16 years in 6 .

In 4 out of 16 patients ( $25 \%$ ), the initial manifestation occurred in infancy or early childhood.
2 of these patients (Cases 14 and 15) had an aneurysmal dilatation of the great vein of Galen, producing obstructive hydrocephalus secondary to $\stackrel{5}{\rightarrow}$ compression and obstruction of the aqueduct of Sylvius (Fig. 1a and b). One of them (Case 15) $\frac{\bar{G}}{\bar{\sigma}}$ was admitted to hospital during the newborn $\frac{\rho}{\sqrt{0}}$ period in congestive heart failure after an upper $\stackrel{\mathbb{D}}{\varrho}$ respiratory infection. A diagnosis of viral myocarditis was made. The patient responded poorly $\vec{\circ}$ to digitalization. However, over a period of 3 ? weeks he improved, and at the time of discharge $\vec{\omega}$ he was asympomatic. At age 3 months he first showed evidence of hydrocephalus. The 응 cardiac failure during the neonatal period may have? been due to the haemodynamic effects of the $\vec{\sigma}$ aneurysm, a complication that is well documented (Levine et al., 1962). The second patient with an $i v$ aneurysm of the vein of Galen, a 6-year-old girl of when first referred, had since early infancy a large 0 head, dilated cervical veins, and a loud cranial bruit which the mother had noted during feedings.

In 3 patients the initial manifestation was a focal motor seizure disorder with a sensory component in one. The seizures in each instance proved to be contralateral to the side of the lesion. General- : ized tonic-clonic seizures were the initial symptom

TABLE I

Clinical and Other Features of 16 Children with Congenital Intracranial Vascular Malformations

\begin{tabular}{|c|c|c|c|c|c|c|}
\hline $\begin{array}{l}\text { Case } \\
\text { No. }\end{array}$ & Sex & $\begin{array}{c}\text { Age at Onset } \\
\text { of First } \\
\text { Symptom } \\
(y r)\end{array}$ & $\begin{array}{c}\text { Age } \\
\text { at } \\
\text { Diagnosis } \\
\text { (yr) }\end{array}$ & $\begin{array}{l}\text { Initial Clinical } \\
\text { Manifestation }\end{array}$ & $\begin{array}{l}\text { Presenting Sign } \\
\text { or Symptom }\end{array}$ & Type of Lesion \\
\hline $\begin{array}{l}1 \\
2 \\
3\end{array}$ & $\begin{array}{l}\mathrm{F} \\
\mathrm{F} \\
\mathbf{M}\end{array}$ & $\begin{array}{r}12 \\
10 \\
2\end{array}$ & $\begin{array}{l}13 \\
30 \\
19\end{array}$ & $\begin{array}{l}\text { Right focal seizures } \\
\text { Subarachnoid haemorrhage } \\
\text { Grand mal seizures }\end{array}$ & $\begin{array}{l}\text { Intracerebral calcification } \\
\text { Subarachnoid haemorrhage } \\
\text { Status epilepticus, increased } \\
\text { intracranial pressure }\end{array}$ & $\begin{array}{l}\text { AV malformation } \\
\text { AV malformation } \\
\text { AV malformation }\end{array}$ \\
\hline 4 & $\mathbf{M}$ & 11 & 11 & $\begin{array}{l}\text { Right hemiparesis, aphasia, } \\
\text { stupor }\end{array}$ & Intracerebral bleeding & AV malformation \\
\hline $\begin{array}{l}5 \\
6\end{array}$ & $\mathbf{M}$ & 1 & $\begin{array}{r}19 \\
19\end{array}$ & $\begin{array}{l}\text { Left leg smaller than right } \\
\text { Left focal seizures }\end{array}$ & $\begin{array}{l}\text { Left focal clonic seizures } \\
\text { Left focal seizures }\end{array}$ & AV malformation \\
\hline 7 & $\mathbf{M}$ & 9 & & $\begin{array}{l}\text { Left central facial paresis, } \\
\text { hemiparesis, and stupor }\end{array}$ & Intracerebral bleeding & AV malformation \\
\hline 8 & $\mathbf{F}$ & 13 & 13 & $\begin{array}{l}\text { Aphasia, hemiparesis and } \\
\text { coma }\end{array}$ & Intracerebral bleeding & AV malformation \\
\hline 9 & $\mathbf{F}$ & 10 & 21 & $\begin{array}{l}\text { Periodic headaches for } 8 \\
\text { years }\end{array}$ & $\begin{array}{l}\text { Prolonged seizures, left } \\
\text { hemiparesis, and left } \\
\text { homonymous hemianopsia }\end{array}$ & AV malformation \\
\hline 10 & $\mathbf{M}$ & 16 & 16 & $\begin{array}{l}\text { Left focal seizures with } \\
\text { prolonged postictal paresis }\end{array}$ & $\begin{array}{l}\text { Left focal seizures with } \\
\text { prolonged postictal paresis }\end{array}$ & AV malformation \\
\hline 11 & $\mathbf{M}$ & 7 & 38 & Grand mal seizures & $\begin{array}{l}\text { Left homonymous inferior } \\
\text { nasal defect }\end{array}$ & AV malformation \\
\hline $\begin{array}{l}12 \\
13\end{array}$ & $\begin{array}{l}\mathbf{M} \\
\mathbf{M}\end{array}$ & $\begin{array}{l}15 \\
12\end{array}$ & $\begin{array}{l}15 \\
12\end{array}$ & $\begin{array}{l}\text { Subarachnoid haemorrhage } \\
\text { Headache }\end{array}$ & $\begin{array}{l}\text { Subarachnoid haemorrhage } \\
\text { Subarachnoid haemorrhage, } \\
\text { coma }\end{array}$ & $\begin{array}{l}\text { AV malformation } \\
\text { AV malformation }\end{array}$ \\
\hline 14 & $\mathbf{F}$ & 1 & 6 & Cranial bruit and large head & $\begin{array}{l}\text { Hydrocephalus, cardiac } \\
\text { enlargement, and left } \\
\text { ventricular hypertrophy }\end{array}$ & Aneurysm of vein of Galen \\
\hline $\begin{array}{l}15 \\
16\end{array}$ & $\begin{array}{l}\mathbf{M} \\
\mathbf{M}\end{array}$ & 1 mth & $\begin{array}{l}3 \mathrm{mth} \\
7\end{array}$ & $\begin{array}{l}\text { Congestive heart failure } \\
\text { Status epilepticus }\end{array}$ & $\begin{array}{l}\text { Hydrocephalus } \\
\text { Status epilepticus }\end{array}$ & $\begin{array}{l}\text { Aneurysm of vein of Galen } \\
\text { Congenital internal carotid/ } \\
\text { internal jugular fistula }\end{array}$ \\
\hline
\end{tabular}




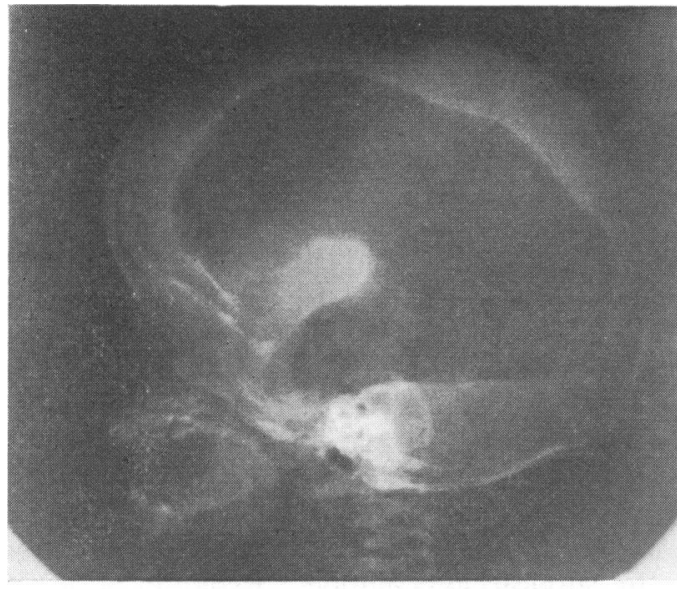

(a)

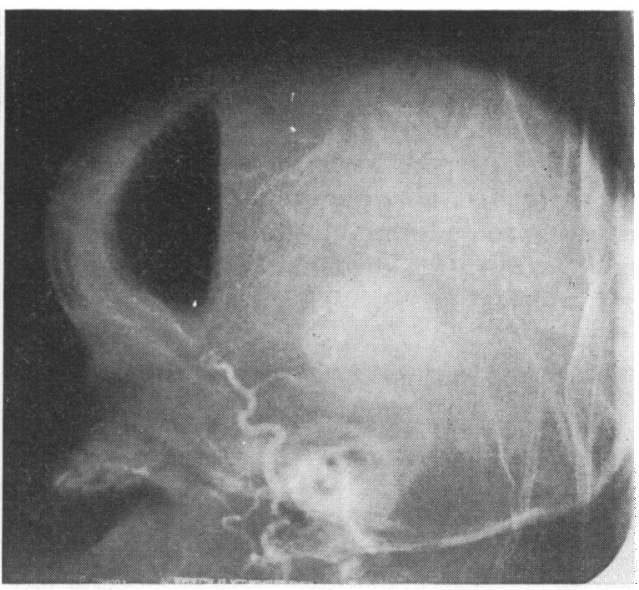

(b)

FIG. 1.-Ventriculogram (a) and angiogram (b) in patient with aneurysm of vein of Galen demonstrating obstructive hydrocephalus. Dilated vein of Galen filled with contrast material.

in 2 patients and status epilepticus in 1 patient. Subarachnoid haemorrhage was the initial manifestation in 3 patients and intracerebral bleeding in another 3. In 1 patient inequality in the size of the legs had been recognized at 1 year of age. Case 16 had an internal carotid/internal jugular fistula (Fig. 2). Though it was not intracranial in location, this congenital vascular malformation has been included because it appears to have been responsible for the death of the patient and because of its extreme rarity (Lagos and Riley, 1970). This patient's illness began one month before admission with right focal seizures. He was

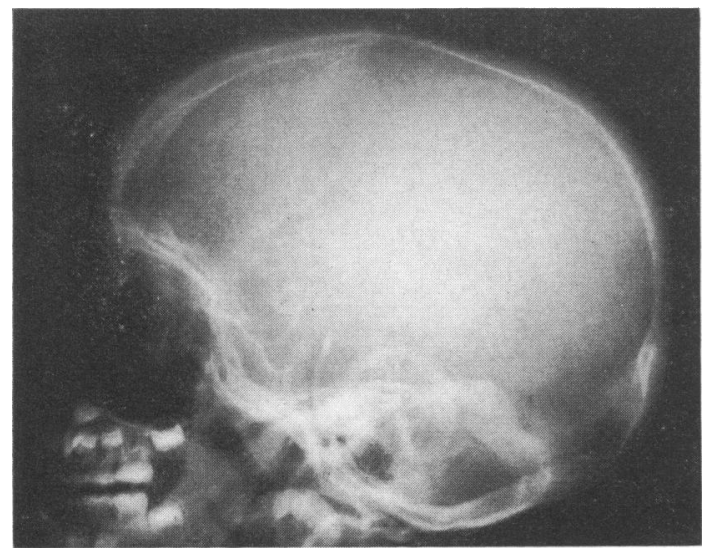

FIG. 2.-Congenital $A V$ fistula between the left internal carotid artery and distal end of the left internal jugular vein. Contrast material diverted from carotid artery into lateral sinus before filling of intracranial portion of artery (from Lagos and Riley, 1970). admitted to Children's Memorial Hospital in a semicomatose state and died in status epilepticus three days after admission.

As shown in Table I, seizure activity and intra-

TABLE II

Location of Vascular Malformation in 16 Children

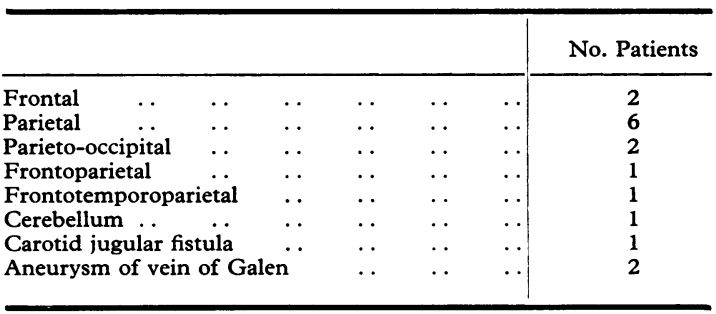

cranial bleeding were the most common presenting manifestations, each occurring in 6 patients. Other presenting findings included hydrocephalus in 2 patients, intracerebral calcification in 1 , and a homonymous visual field defect in 1 . Only one patient, a 10-year-old girl, complained of headache. This is in contrast with the frequency of this symptom in adults with intracranial vascular malformations in whom periodic migrainous headaches occur in about $15 \%$ of cases (Mackenzie, 1953).

As mentioned above, intracranial bleeding was the initial clinical manifestation in 6 children. In 3 patients the bleeding was subarachnoid in nature and accompanied by sudden onset of headache, meningeal signs, and mental confusion. Three patients were admitted to the hospital with 
signs of intracerebral bleeding (sudden loss of consciousness, third nerve palsy, hemiparesis, decreased or increased muscle stretch reflexes, and unilateral or bilateral extensor plantar response).

Table II shows the location of the lesions. In general there was a strong tendency for the AV malformation to be located in the parietal or frontoparietal area in the distribution of the middle cerebral artery (Fig. 3). There was no particular

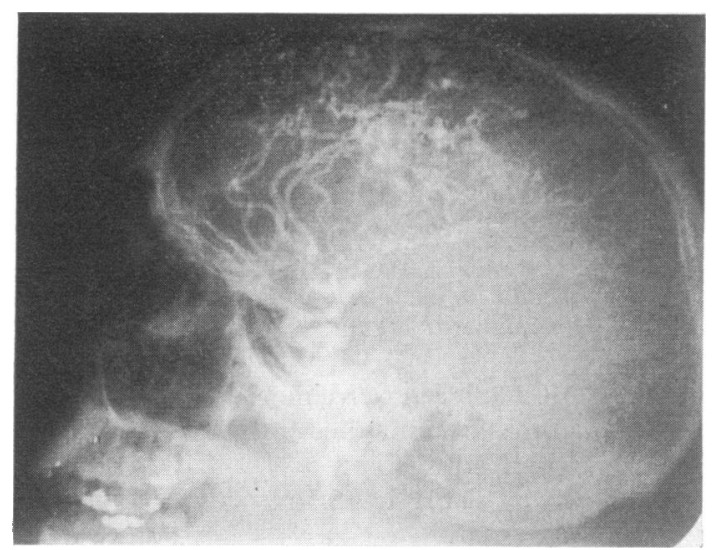

Fig. 3. $-A V$ malformation in frontoparietal region.

predominant hemisphere in which these lesions were found. In 2 patients the AV malformation was located in the frontal region and in 10 it involved primarily the parietal region, with varying degrees of involvement of adjacent areas. Case 13 had sudden onset of headache followed by coma and death 6 hours after admission. Necropsy revealed a cortical AV malformation of the cerebellum. 2 patients had an aneurysm of the vein of Galen and one a left internal carotid artery/ internal jugular vein fistula in the upper neck.

Examination of the CSF was of no diagnostic aid except in those patients presenting with subarachnoid haemorrhage.

Radiological examination of the skull revealed areas of intracranial calcification in 3 patients, the youngest being 12 years of age. EEG showed focal slowing on the same side as the lesion in only one patient. Generalized arrhythmias were $\omega$ encountered in patients with cerebrovascular accidents who at the time of admission were stuporous or comatose.

Seven of the patients in this series were subjected to surgical intervention. Removal of a vascular malformation or an intracerebral haematoma secondary to rupture of the lesion was performed in these 7 patients. All survived operation but, in general, surgical intervention was associated with many transient or permanent complications such as hemiparesis or aphasia. The only favourable result after operation was the control of seizures in 2 patients. Neurological sequelae in patients with intracerebral bleeding included permanent hemiparesis and varying degrees of homonymous hemianopsia in 4 patients, aphasia in 1, and poor control of seizures in 2 . Further subarachnoid haemorrhage occurred in 1 patient. 2 patients were treated without success with cobalt radiotherapy because of the surgical inaccessibility of the lesion. In one of the patients with an aneurysm of the vein of Galen and hydrocephalus, clamping of the feeding vessels was performed (Fig. $4 a$ and $b$ ).

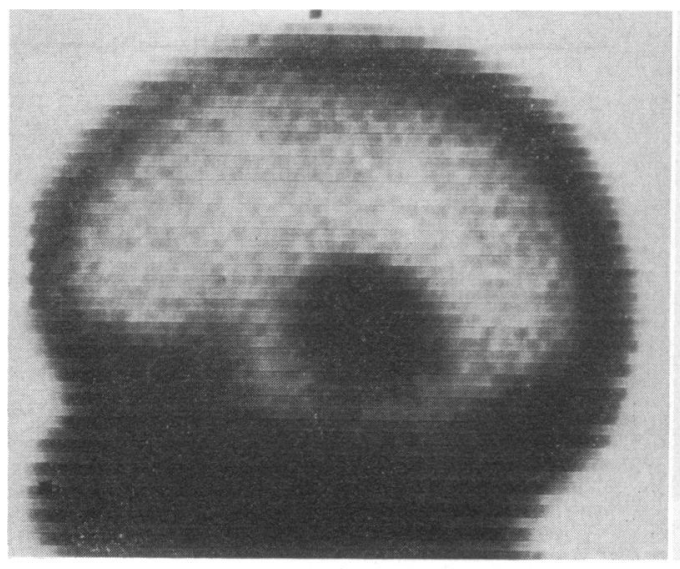

(a)

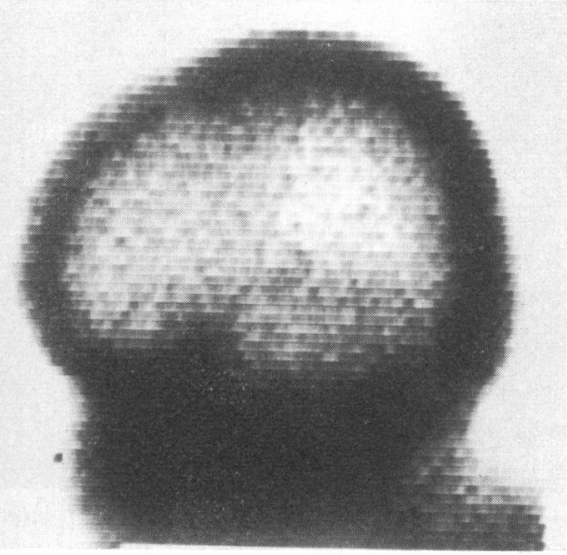

(b)

FIG. 4.-(a) Increased uptake of radioisotope in patient with vein of Galen aneurysm. (b) Very decreased uptake of radioisotope in same patient after surgical clamping of feeding vessels. 
Operation was followed by a conspicuous reduction in the size of the aneurysm, as shown by a decreased radioisotope uptake.

\section{Discussion}

Ford (1966) has classified congenital intracranial vascular malformations as follows: (1) saccular aneurysms of the cerebral arteries, (2) arteriovenous aneurysms or arteriovenous fistulae, (3) venous angiomas, (4) telangiectases, (5) meningeal angiomatosis or the Sturge-Weber syndrome, and (6) familial cerebellar ataxia with choreoathetosis, telangiectasia, and infections of the respiratory tract (ataxia-telangiectasia syndrome). Of these, $\mathrm{AV}$ malformations are the most common in infancy and childhood and occur ten times more frequently than intracranial aneurysms (Barnett, 1968).

In 1966, the Co-operative Study of Intracranial Aneurysms and Subarachnoid Hemorrhage reported on 4880 patients presenting with a single attack of subarachnoid haemorrhage (Perret and Nishioka, 1966). Of these, 128 patients (3\%) were in the paediatric age group. Based on the causes of subarachnoid haemorrhage, the patients were divided into three groups: (1) those with aneurysms, (2) those with arteriovenous malformations, and (3) those in whom 'other causes' were responsible (tumours, blood dyscrasias, idiopathic subarachnoid haemorrhage, and others). In the $0-4$ age group there were 7 patients: in 1 there was an intracranial aneurysm and in 6 patients subarachnoid haemorrhage was apparently due to 'other causes'. In the 5-9 age group there were 15 cases: 6 aneurysms, 3 arteriovenous malformations, and 6 'other causes'. In the 10-14 age group (30 patients), aneurysms were identified in 7 patients, arteriovenous malformations in 12, and 'other causes' in 11. Finally, in the 15-19 age group (76 patients) there were 27 aneurysms, 25 arteriovenous malformations, and 24 subarachnoid haemorrhages from 'other causes'. Though the study is somewhat biased (some of the participating institutions had limited paediatric services), it is clear that subarachnoid haemorrhage is relatively rare in children $(3 \%$ of all cases). In this study, in contrast to certain others, the incidence of subarachnoid haemorrhage due to aneurysms, AV anomalies, and 'other causes' is approximately the same except in the 0-4 age group in which 'other causes' predominate. In the overall series, males were affected more commonly than females by a ratio of $3: 1$.

As mentioned previously, though a significant number of patients with congenital intracranial vascular malformations show manifestations during infancy and childhood, the diagnosis is made infrequently ante mortem during these ages. Thus, one of the primary purposes of this study was to analyse the symptoms and signs of congenital intracranial vascular malformations in children, which were present before the occurrence of more serious manifestations, in an effort to diagnose these lesions earlier and thereby allow more appropriate treatment. These manifestations were of three general types. (1) Seizures: this was the earliest manifestation in 6 patients; in 3 the seizures were focal and in 3 status epilepticus or generalized seizures occurred. (2) Neurological manifestations secondary to the local cerebral dysfunction produced by the malformations: hemiparesis was the initial manifestation in 3 patients and in 2 patients was accompanied by aphasia; in 1 patient the initial abnormality was a disproportion in the size of the lower extremities. (3) Intracranial bleeding: this was the earliest finding in 6 patients. The earliest sign in one patient was a cranial bruit, and, in another with an aneurysm of the great vein of Galen, a large head and congestive heart failure.

The previous observations clearly indicate that the diagnosis of congenital intracranial vascular malformations is often very difficult to make, and that its treatment, once the diagnosis is obvious because of the occurrence of a cerebral catastrophe, is far from satisfactory.

This analysis suggests the following diagnostic recommendations. Careful auscultation of the entire skull should be performed in all infants with cardiac failure (for this purpose a stethoscope with rubber bell is preferable to one with a metallic bell). Soft bruits over the eyeballs, temporal areas, or the entire skull are heard in about $22 \%$ of febrile and $16 \%$ of afebrile children (Mace, Peters, and Mathies, 1968). Any loud bruit, especially if unilateral, deserves further investigation. It is well known that cranial bruits are rarely heard in patients with AV malformations presenting with signs or symptoms of intracranial bleeding. If the 6 patients presenting with intracranial bleeding are excluded, a cranial bruit was heard in $40 \%$ of patients. This incidence is in accordance with previous reports regarding the frequency of cranial bruits in these types of malformations (Mackenzie, 1955). A careful search should also be made for focal or lateralizing neurological signs such as visual field defects and extensor plantar response. It is the authors' impression that these signs are the chief ones of which the patient or the parents may not be aware. Other general or focal signs or symptoms such as headaches, muscle weakness, sensory deficit, or lack of co-ordination rarely cause con- 
fusion because in almost all instances they are volunteered by the patient or the parents. In this series focal seizures tended to occur at any age, whereas intracranial haemorrhage was seen usually in late childhood, adolescence, or early adulthood. Patients with focal seizures refractory to anticonvulsant therapy or those in which the type of seizure changes in character or recurs after an asymptomatic period should be examined at frequent intervals. We believe that any child with a seizure disorder who develops abnormal neurological signs deserves contrast radiological studies. Radiological examination of the skull, particularly in older children, may show intracerebral calcifications. Occasionally, the EEG especially in the presence of a large and superficially located $A V$ malformation, may show a slow wave focus. Brain scanning appears to be useful in detecting and localizing non-neoplastic lesions such as AV malformations or intracerebral haematomas; it proved helpful in one patient in our series. A definite aetiological and localizing diagnosis can be be made only by angiography. This is a relatively safe procedure and is not difficult to perform in older children. Occasionally the neurologist or neurosurgeon will encounter some difficulties in performing percutaneous angiography in small children or infants due to the small calibre of the blood vessels. The paediatric cardiologist, with his ability to place a catheter almost anywhere, has been of great help to us under these circumstances.

The therapeutic management of patients with congenital cerebral AV malformations is complex, and each case must be treated individually; unfortunately therapy continues to be generally unsatisfactory.

We thank Drs. J. Nicholson and R. C. Gilmartin for their assistance in various parts of this study.

\section{REFERENCES}

Barnett, H. L. (1968). Pediatrics. 14th ed., p. 931. AppletonCentury-Crofts, New York. Butterworth, London.

Carroll, C. P. H., and Jakoby, R. K. (1966). Neonatal congestive heart failure as the presenting symptom of cerebral arteriovenous malformation. Fournal of Neurosurgery, 25, 159.

Ford, F. R. (1966). Diseases of the Nervous System in Infancy, Childhood and Adolescence, 4th ed., p. 920. C. C. Thomas, Springfield, Illinois.

Gilmartin, R. C., and Riley, H. D., Jr. (1965). Congenital intracranial vascular malformations in infancy and childhood. Annual Meeting, Southern Society for Pediatric Research, Louisville, Kentucky, 5 Nov. 1965. Listed in Southern Medical Fournal, 58, 1573.

Gold, A. P., Ransohoff, J., and Carter, S. (1964). Vein of Galen malformation. Acta Neurologica Scandinavica, 40, Suppl. 11.

Lagos, J. C., and Siekert, G. R. (1969). Intracranial hemorrhage in infancy and childhood. Clinical Pediatrics, 8, 90.

Lagos, J. C. and Riley, H. D., Jr. (1970). Congenital internal carotid-internal jugular fistula. Fournal of Pediatrics, 77, 870.

Leites, F. L. (1957). Angiomas of the brain causing sudden death in children. (Russian.) Arkhiv Patologii, 19 (5), 61.

Levine, O. R., Jameson, A. G., Nellhaus, G., and Gold, A. P. (1962). Cardiac complications of cerebral arteriovenous fistula in infancy. Pediatrics, 30, 563.

Mace, J. W., Peters, E. R., and Mathies, A. W. (1968). Cranial bruits in purulent meningitis in childhood. New England fournal of Medicine, 278, 1420.

Mackenzie, I. (1953). The clinical presentation of the cerebral angioma. A review of 50 cases. Brain, 76, 184

Mackenzie, I. (1955) The intracranial bruit. Brain, 78, 350.

Olivecrona, H., and Riives, J. (1948). Arteriovenous aneurysms of the brain. Their diagnosis and treatment. Archives of Neurology and Psychiatry, 59, 567.

Paillas, J. E., Bérard-Badier, M., Bonnal, J., and Serratrice, G. (1956). Angiomes artério-veineux du cerveau chez l'enfant (à propos de 5 observations avec contrôle opératoire). Revue Neurologique, 94, 279.

Paillas, J. E., Bonnal, J., Bérard-Badier, M., and Serratrice, G. (1958). Les angiomes artério veineux du cerveau chez l'enfant. Presse Medicale, 66, 525.

Paterson, J. H., and McKissock, W. (1956). A clinical survey of intracranial angiomas with special reference to their mode of progression and surgical treatment: a report of 110 cases. Brain, 79, 233.

Perret, G., and Nishioka, H. (1966). Report on the cooperative study of intracranial aneurysm and subarachnoid hemorrhage. IV. Cerebrospinal angiography. Fournal of Neurosurgery, 25, 98.

Thomson, J. L. G. (1959). Aneurysm of the vein of Galen. British fournal of Radiology, 32, 680.

Correspondence to Dr. J. C. Lagos, Children's Memorial Hospital, University of Oklahoma Medical Center, 800 N.E. 13th Street, Oklahoma City, Oklahoma 73104, U.S.A. 